No bands were found in a specimen fatigued at liquid-air temperatures.

The existence of many potential slip bands in age-hardened alloys undergoing fatigue provides an additional explanation of the poor fatigue properties of some age-hardening alloys relative to their static strength properties. Besides the possibility of overageing, slip can more readily occur in any one crystal and be transmitted to its neighbours. The alloy described is simply a super-pure version of a common commercial alloy, and it is of interest that crystallographic cracking can be found in such an alloy, although its analysis is complicated by the presence of gross inhomogeneities and intermetallics (Fig. 4).

T. Broom

V. N. WHITTAKER

Department of Industrial Metallurgy,

University of Birmingham.

Nov. 8.

${ }^{1}$ Orowan, E., Proc. Roy. Soc., A, 171, 79 (1939).

${ }^{2}$ Broom, T., and Molineux, J. H., J. Inst. Metals, 83, 528 (1954-55).

${ }^{3}$ Karnop, R., and Sachs, G., Z. Phys., 49, 480 (1928): Carlsen, K. M., and Honeycombe, R. W. K., J., Inst. Metals, 83, $449(1954-55)$ 4 Franz, E. C., J. Metals, 6, 56 (1954).

${ }^{5}$ Boas, W., and Ogilvie, G. J., Acta Metallurgica, 2, 655 (1954).

\section{Apparent Velocity of Alpha-Particles in Cloud Chambers}

Visual demonstration of $\alpha$-tracks in cloud chamber's, especially of the diffusion type, sometimes gives the impression that the tracks actually shoot out from the radioactive source in a fraction of a second (not unlike the smoke trail of a train moving in a distant landscape, though the time-scale is different). It is curious not to find this effect mentioned in the literature, though it must baffle those teachers that have to correct their pupils when they think it is the actual velocity of the particles they cre observing.

We suggest the phenomenon is due to the finite diffusion-rate of vapour molecules to the droplets that are forming, their growth being slower at the end of the track because of the stronger competition due 10 the larger density of ionization. Assuming the known values of this density and assuming the track to be a cylindrical sink in the diffusion field, we find the right order of magnitude for the retardation at the end, the track being fully developed in somewhat less than a second near the end, and in about half that time in the central part.

On a similar basis rests the explanation of a related condensation phenomenon that may be observed with yet simpler means. When one looks at a small light source through a flask with moist air in which on adiabatic expansion is produced (for example, by sucking through a rubber tube) a coloured diffraction halo around the light source is seen. It is, however, not stationary, but at first moves inward during a fraction of a second. This must be attributed to an increase in the size of the fog droplets, due to the same finite diffusion-rate of the water vapour (and of the heat dissipation). Here the sink to be used in the calculation is the spherical droplet itself.

$$
\text { J. A. PRINS }
$$

S. A. Hempentus

Technical Physics Laboratory,

Technical University,

Delft.

Oct. 3.

\section{An Unusually Radioactive Fossil Fish from Thurso, Scotland}

DuRING recent investigations on the distribution of radioactive elements in phosphates ${ }^{x}$, it was noted that many of the Old Red Sandstone fish remains from north-east Scotland have an abnormally high radioactivity ; in particular an unidentified Homostius plate (GSM 89090) was shown by rough radiometric assay to have an activity equivalent to 0.5 per cent $\mathrm{U}_{3} \mathrm{O}_{8}$.

More detailed radiometric assays we have carried out indicated that this material is either in a state of secular disequilibrium, or contains appreciable amounts of thorium. As the latter alternative seemed the more likely, part of the specimen was assayed chemically (Radiochemical Group, Chemical Research Laboratory, Teddington) and found to contain $0 \cdot 32$ por cent $\mathrm{U}_{3} \mathrm{O}_{8}$ and 0.51 per cent $\mathrm{ThO}_{2}$, a result which is in excellent agreement with the equivalent $\mathrm{U}_{3} \mathrm{O}_{8}$ value of 0.4 .8 per cent obtained on the same sample. On obtaining chemical confirmation that appreciable thorium is associated with this particular fish plate, additional investigations were undertaken in an endeavour to obtain more information on the distribution of the radioactive elements within the plate.

In thin section the plate is opaque except where small amounts of interstitial calcite occur; but in polished section the bone structure can be scen clearly (Fig. 1). The bone cavities are filled with hydrocarbon or hydrocarbon partly replaced by calcite. Accessory minerals recognized in the polished sections are pyrite and chalcopyrite.

The mineral constituting the bone tissue was identified by normal optical methods and by X-ray powder photographs of an untreated sample, and of a similar sample ignited to destroy the associated hydrocarbon. Powder photographs of fluorapatite and of carbonate-fluorapatite were also taken for comparison purposes. The X-ray data on which the identification is based are given in Table 1 .

It is apparent from the above observations that the apatite of the bone matrix has an $a$ cell dimension between carbonate-fluorapatite and fluorapatite, but a $c$ dimension somewhat greater than the other carbonate-fluorapatites examined. The refractive indices of the ashed material, $\omega=1.628$ and $\Sigma=$ $1 \cdot 616$, however, are in good agreement with carbonatefluorapatite, and since fluorine and only a trace of chlorine were detected chemically (C. O. Harvey, Geological Survey and Museum), it seems reasonably certain that the Thurso material is in fact a carbonatefluorapatite.

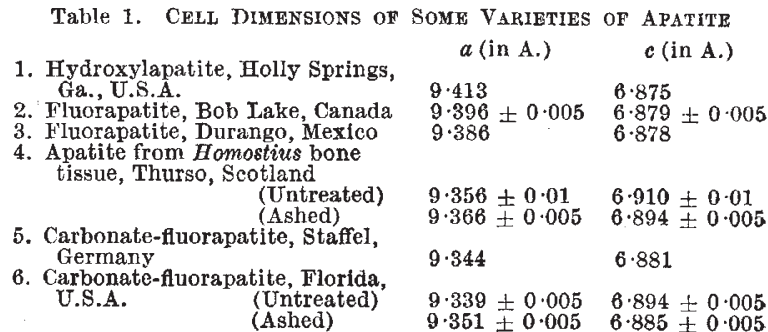

Determinations 1, 3 and 5 are by Z. S. Altschuler, E. A. Cisney and I. H. Barlow using an $X$-ray diffractometer. Abstract in C.R. $X I X$ Int. Geol. Congr. Algiers, 11, 9 (1952).

In determinations 2,4 and 6 a $114 \cdot 6-\mathrm{mm}$. diameter camera was used with copper $K a$ radiation and an internal standard of potassium chloride ; $a$ was determined from the reflexion $41 \overline{50}$ and $c$ from 0004 . 